\title{
The accuracy of cutting edge wear measurement using a focus-variation microscope
}

\author{
Dokładność pomiaru zużycia krawędzi skrawających \\ z wykorzystaniem mikroskopu różnicowania ogniskowego
}

\author{
JAN BUREK \\ BARBARA JAMUŁA *
}

An assessment of the accuracy of the reconstruction of cutting edges 3D geometry shank cutter depending on the magnification of the lens is presented. Focus-variation microscope Alicona G4 with IFM Alicona software were used in the research. The main goal of the research was to determine differences created in the process of the reconstruction of cutting edges geometry. Three-dimensional maps of deviation values were presented, using measurements of cutting edges geometry.

KEYWORDS: measurement accuracy, focus-variation, cutting edge geometry

Monitoring the wear of the cutting tool after a certain working time is one of the key factors guaranteeing the stability of the machining process [5]. Cracks, chipping, defects of material etc. that appear on the cutting tool's cutting edge during machining are difficult to detect by the operator. Lack of verification of the deteriorating machining properties of the tool has a significant impact, among others on: increase of cutting forces, geometrical structure of the workpiece surface and condition and life of the tool.

To meet the requirements for cutting tools, it is necessary to extend the scope of monitoring their condition after a fixed period of work [2]. The condition of the tool blades is primarily influenced by the type, size and area of wear on the surface of the cutting edges. The choice of the measurement device is determined by the resolution and traceability of the image, as well as the time to obtain the measurement results.

These expectations are met by Alicona's Infinite Focus fire divider microscope. A wide spectrum of measurement technologies with this device allows for the control of geometry, wear and roughness on the cutting surfaces of the cutting tool [1]. Due to the combination of optical, surface and coordinate measuring technology, the leading manufacturers of cutting tools use Alicona's measuring technology to obtain information on the quality of tools. The measurement data of the cutting tool allows you to design

\footnotetext{
* Dr hab. inż. Jan Burek prof. PRz (jburek@prz.edu.pl), mgr inż. Barbara Jamuła (b.jamula@prz.edu.pl) - Katedra Technik Wytwarzania i Automatyzacji, Wydział Budowy Maszyn i Lotnictwa Politechniki Rzeszowskiej
}

its geometry and maintain control over individual stages of the manufacturing process.

In contrast to other measuring techniques, the focal length microscope allows you to measure objects on a micro and macro scale [3]. A precise optics, including various lens systems, is an essential element of this system. Thanks to the equipment with measuring lenses, it is possible to conduct tests with a variable magnification value and a different field of vision.

Measuring the microscope of the geometry of the cutting tool with the technique of focal differentiation requires the selection of appropriate lenses, especially if the user needs information about the place of wear at the cutting edges and wants to determine its type.

In order to ensure the required accuracy of mapping the wear of the cutting edge of the tool, it is necessary to determine the methodology of the measurement of focal differentiation technology. An important issue is to check this method in terms of measurement accuracy with different magnification values, depending on the wear level of the cutting tool edge.

\section{Test conditions}

The tests were carried out on a three-axis Infinite Focus G4 (microscope) system from Alicona with an additional IFReal3D RotationUnit rotating unit, enabling full 3D scanning of the cutting tool geometry (fig. 1). Infinite Focus uses an innovative and independent Focus-Variation technique. It uses measurement technology based on focal differentiation, the description of which can be found in the norm EN ISO 25178.

The accuracy of the cutter wear measurement was evaluated using three types of lenses allowing the measurement of the cutting edge with a magnification of: $2.5 x ; 5 x ; 10 x$. Selected data on G4 lenses of the Infinite Focus microscope are presented in the table [4].

Polarization was applied during measurements. According to the microscope manufacturer's documentation, polarization is needed when the surface is not uniformly illuminated. As a result, direct reflection from the metal surfaces is extinguished and only a diffuse reflection remains. The image obtained does not depend on the inclination of the measured object, but on the texture of the surface. 
TABLE. Measurement results

\begin{tabular}{|l|c|c|c|}
\hline Enlarging the lenses & $2.5 \times$ & $5 \times$ & $10 \times$ \\
\hline Field of view $X, \mu \mathrm{m}$ & 5716 & 2858 & 1429 \\
\hline Field of view $Y, \mu \mathrm{m}$ & 4351 & 2175 & 1088 \\
\hline Working distance, $\mathrm{mm}$ & 8.8 & 23.5 & 17.5 \\
\hline $\begin{array}{l}\text { Minimal repeatability, } \\
\mathrm{nm}\end{array}$ & 800 & 120 & 30 \\
\hline Resolution, pkt & $1624 \times 1232$ & $1631 \times 3286$ & $1642 \times 5358$ \\
\hline
\end{tabular}

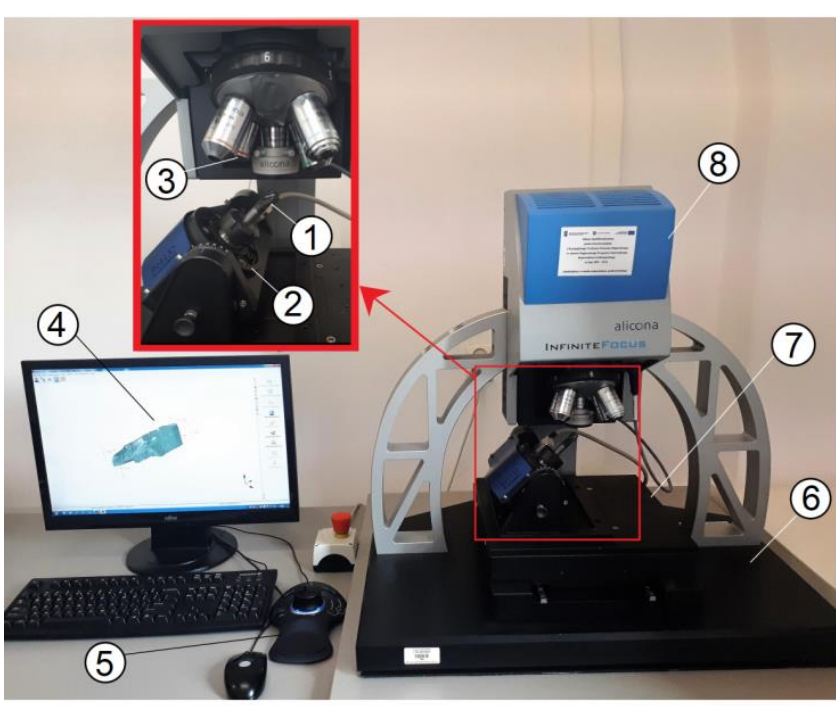

Fig. 1. Alicona's Infinite Focus G4 measuring stand: 1 - a cutting tool, 2 - rotating unit, 3 - lens revolvers, $4-3 D$ geometry of the cutting edge of the analyzed cutter, 5 - joystick allowing positioning of the measured object, 6 - table with passive vibration absorption system, 7 - table moving in the $X Y$ axis, 8 - sensor head with light source

Due to the high degree of light reflection and in order to improve the accuracy of image recording for each lens, ring lights with a polarizing disc were also mounted. The use of a polarizing filter eliminated the obtaining of an image showing large differences in brightness, as well as with surfaces too dark for measuring the $3 \mathrm{D}$ edge geometry of the cutting tool [4].

A four-sided monolithic carbide burr was used with visible places of wear on the surfaces of cutting blades (fig. 2).
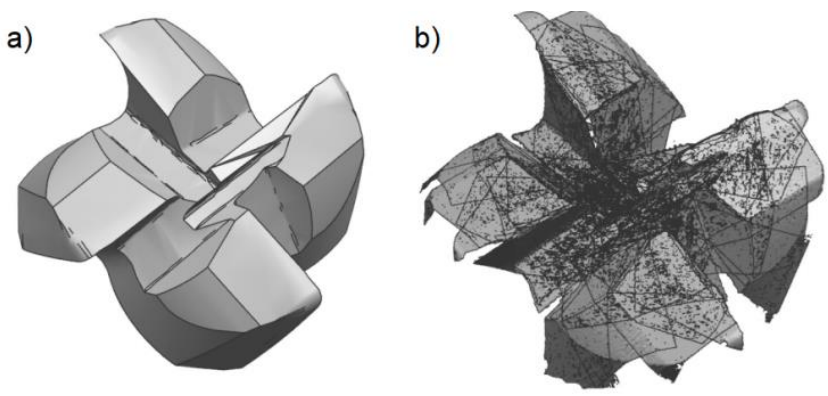

Fig. 2. 3D geometry of the blades of a four-edged monolithic end mill: a) a model of a new cutter, b) a model of a used cutter obtained on the basis of measurements

The analyzed cutter was placed in the rotary holder at an angle of $45^{\circ}$, and then the lens was moved to the upper limit ( $Z$ axis) of the measuring range by means of a joystick and the upper limit was determined. The definition of the lower boundary was the same. After determining these parameters, the measurement was recorded.

The three-dimensional image of the edge of the cutting tool was displayed in the 3D-Viewer of the Alicona IMF program. During the tests, measurements were taken for each milling edge of the milling cutter depending on the changing value of the magnification of the lens.

\section{Results of the test}

The results obtained from the optical measuring system, in the form of three-dimensional geometries of the cutting edges, allowed to evaluate the accuracy of the tool measurement and its wear at various magnifications. Based on the recorded images, the time of mapping the edge geometry of the cutting tool was determined (fig. 3 ).

It was noted that the 3D geometry mapping time for each cutting edge of the analyzed cutter with a $2.5 \times$ objective was the shortest (compared to the data obtained at another increase). Based on the obtained three-dimensional geometries, it can be concluded that the scanning time is dependent on the field of view of the objective lens. This means that the greater the magnification of the lens, the longer the scanning time of the cutting edge.

This is due to the combination of images, the number of which depends on the field of view of a given lens. For a $2,5 \times$ objective lens, one scanned image was obtained, and in other cases, the IMF software combined images. For a $5 \times$ magnification lens, these were two images, and in the case of $10 \times$ magnification - three images.

The cutting edge geometry time was max. $1.5 \mathrm{~min}$. It is relatively short, and the obtained three-dimensional geometry of the cutting edge allows control and accurate analysis of the defects and irregularities on the surfaces of the cutting tool blades.

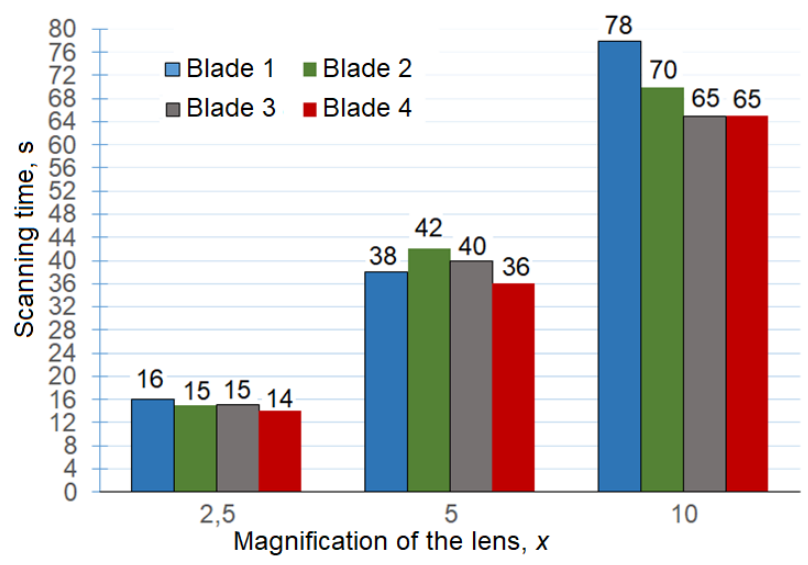

Fig. 3. Time of scanning the cutting edge geometry of the milling cutter depending on the magnification of the lens

The spatial surfaces of cutting edges of the cutter obtained as a result of measurements were compared in one of the applications (DifferenceMeasurement) of the IMF program from Alicona. This was to create a map with deviation values (fig. 4). These values were achieved by fitting (using the Automatic Alignement method, fig. 5) threedimensional geometries of cutting edges obtained from measurements with different magnification values of the lens. The accuracy of the measurement was determined on the basis of the deviations between the surfaces obtained.

It is noted that the deviation values vary depending on the magnification of the lens. The biggest deviations were obtained as a result of comparing the area with a magnification of 10 -fold and 2.5 -fold. The smallest value of deviations was obtained from the comparison of the area at 2.5-fold and 5-fold.

When comparing images with the same magnification values, deviations are comparable. The change is visible only on side surfaces, where the deviation value is even $0.04 \mathrm{~mm}$. 

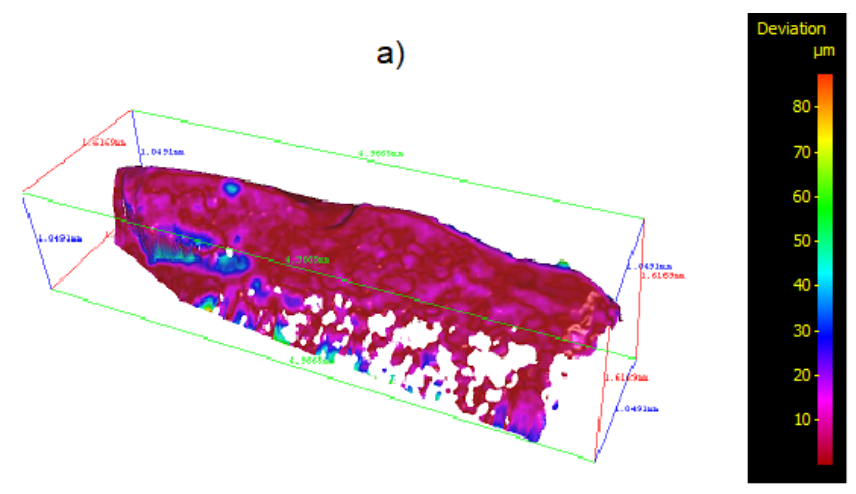

b)

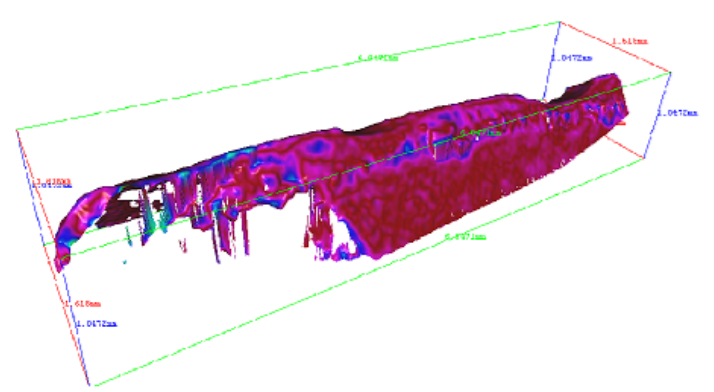

Fig. 4. Maps of cutter cutting edge deviations with a magnification of $2.5 \times$ and $5 \times$ : a) Front view of the edge, $b$ ) Rear view of the edge

a)

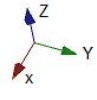

b)

c)
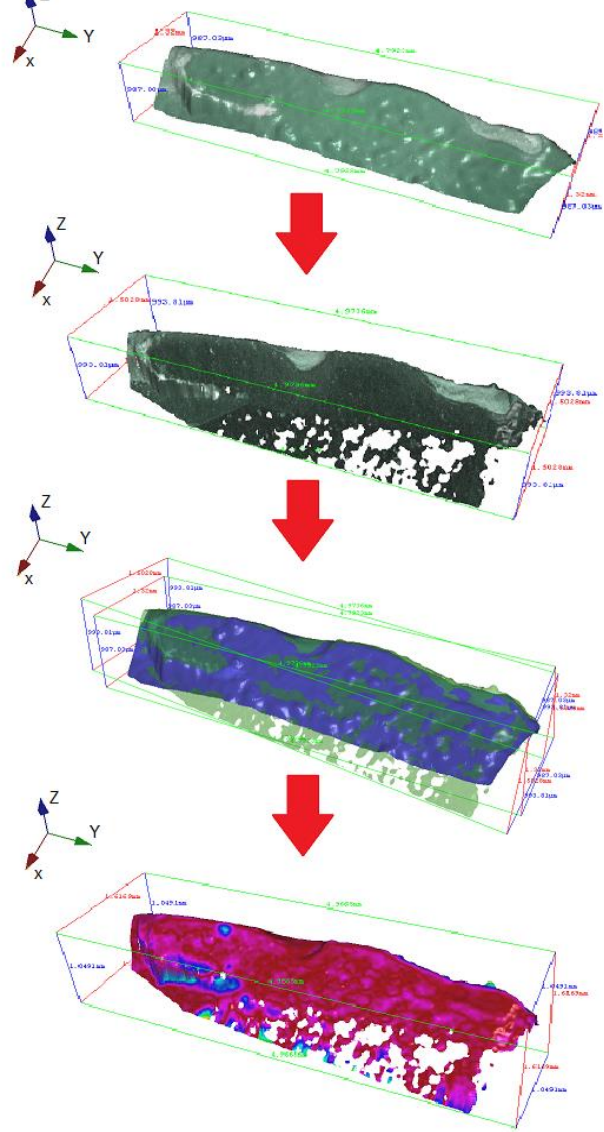

Fig. 5. Comparison scheme for three-dimensional edge-breaking models resulting in maps with deviation values: a) angled hau obtained from a magnification of $2.5 \times, b$ ) edge obtained from enlargement of $5 \times, c$ ) edge adjustment $a$ and $b, d$ ) the map of deviation values

Particular attention was paid to the three-dimensional surface of the cutting edge of the used cutter received at a magnification of $10 \times$. Places where the cutting edge geometry has not been reproduced are observed. These paintings present numerous deficiencies in the form of holes. These defects are clearly visible on the surface of the main application. In addition, the geometries scanned with this resolution show significant unevenness on the side surfaces of the cutting edge (fig. 6).

In the $5 \times$ magnified images, the number of holes on the lateral edges of the cutting edge was also noticed. By comparing the three-dimensional images obtained from the $5 \times$ and 10x magnification lens in the Difference Measurement application, a significant increase in the overlap time of the measured surfaces was observed. Some of them, after using automatic matching, could not find nominal surfaces. Hence, the time to obtain maps with deviations in dimensional values was significantly longer. It has been noticed that the choice of a higher resolution of the lens results in a deterioration of the quality of the mapping of the three-dimensional edge geometry of the cutting tool and an increase in the waiting time for the measurement results.

\section{Conclusions}

The use of the differential focus technology in the Infinite Focus microscope allows for measurements on a micro and macro scale with different magnification of the lens. The selection of this value for the measurement and assessment of wear on the blades, and in particular the cutting edges, largely depends on the time of obtaining the results and the accuracy of the representation of the geometry of the blades.

The research shows that the lens with a magnification of $2.5 \times$ obtains the best reproduction in the form of threedimensional images - both areas of wear at the edges of the cutting tool blades, as well as the entire geometry of the blade. The scanning time of the cutting tool blades with a $2.5 \times$ magnification lens is the shortest.

The results obtained above all give the opportunity to enlarge the lenses to measure the edge geometry of the cutting tool and the entire tool geometry.

\section{REFERENCES}

1. Brzozowski D., Wieczorkowski M., Gapiński B. „Pomiar geometrii i ocena powierzchni narzędzi za pomocą mikroskopu różnicowania ogniskowego". Mechanik. 11 (2017): pp. 1020-1022.

2. Burek J. „Nadzorowanie procesów obróbki skrawaniem i obróbki ściernej". "Rzeszów: Oficyna Wydawnicza Politechniki Rzeszowskiej, 2018.

3. Gapiński B., Wieczorkowski M., Marciniak-Podsadna L., Dybala B., Ziółkowski G. "Comparison of different method of measurement geometry using CMM, optical scanner and computed tomography 3D". Procedia Engineering. 69 (2014): pp. 255-262.

4. Infinite Focus Alicona 3.5.1.5 - podręcznik IFM, 2011.

5. Szafarczyk M., Chrzanowski J., Gościniak R. „Nowoczesne metody monitowania zużycia ostrzy narzędzi". Materiały Konferencji „Innowacje w budowie i eksploatacji maszyn”. Poznań, 2006.

Translation of scientific articles, their computer composition and publishing them on the website www.mechanik.media.p by original articles in Polish is a task financed from the funds of the Ministry of Science and Higher Education designated for dissemination of science.

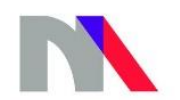

Ministry of Science and Higher Education

Republic of Poland 